\title{
Serious Play as a Method for Process Design
}

\author{
Mary Dempsey ${ }^{1}$, Ralph Riedel ${ }^{2}$, and Martina Kelly ${ }^{1}$ \\ ${ }^{1}$ National University of Ireland Galway, College of Engineering and Informatics, \\ Galway, Ireland \\ \{mary.dempsey, martina kelly\}@nuigalway.ie \\ ${ }^{2}$ Technische Universität Chemnitz, Factory Planning and Factory Management, Germany \\ ralph.riedel@mb.tu-chemnitz.de
}

\begin{abstract}
As motivating and including people is a crucial aspect in any planning, design and change process there is always a need for appropriate methods and tools to support this. Lego Serious Play (LSP) is such a method which was developed to facilitate among others communication, creativity and shared mental models. In this paper the application of LSP is demonstrated for the case of re-designing a product development lifecycle process. With the case study we pursue a qualitative approach to seek for support that LSP is able to support team building and team decision processes, to avoid typical pitfalls of groupthink which will finally lead to solutions of higher quality, to efficient processes and to satisfied participants.
\end{abstract}

Keywords: Lego Serious Play, new product development, process design, participative design processes.

\section{$1 \quad$ Introduction}

Due to current challenges from a dynamic and global economy enterprises are forced to maintain and improve competitiveness. This requirement for improvement is mainly based on effective and efficient processes as well as innovative products and services. The need for flexible and competitive processes encompasses not only production and logistics but also the necessary supportive and administrative processes. It also extends to early activities in the product lifecycle such as product development. Well-established principles already exist for the efficient design of production and logistics processes, many of which have been developed within the Lean Management paradigm. With respect to supportive and administrative processes, business process re-engineering (BPR) and business process management (BPM) techniques are well supported. However, when faced with new product development and the product development lifecycle process, greater challenges exist. Due to the inherent complexity of process analysis and process design, enterprises tend to follow heuristic principles. These principles are based predominately on the knowledge of the people involved in the processes. Moreover, in every process and organizational design endeavor the people affected need to be involved not only for their specialist know-how but they must identify with and accept the solution in order to guarantee a successful outcome. 
As motivating and including people is a crucial aspect in any change process there is always a need for methods and tools to support this. Serious Play approaches are one approach to not only unleashing people's creativity but also including them actively in the creative problem solving processes and thereby building identity with the developed solution. LEGO® SERIOUS PLAY $®$ (LSP) was developed to be an innovative, experiential process and has been shown to extend players' awareness of problems and ideas, and to enhance creativity and enable teamwork. This paper details the results of a case study which uses LSP as a tool to support the development of an effective New Product Development Life Cycle (NPDLC) process.

\section{Theoretical Background and Methodology}

\subsection{Process Reengineering and Implementing Change}

Evaluating, rethinking and reengineering are increasingly seen as a way to improve the productivity, product quality and operations of a company [1]. Hereby, it is widely agreed that the implementation phase of a newly designed process is of major concern [2]. Solving technological and project planning issues are necessary, but not sufficient, preconditions for the success of a process reengineering endeavor [2]. Reengineering processes, especially creative and collaborative processes like product development or production planning, are complex, involving numerous factors and especially people from different, heterogeneous backgrounds [2]. The literature suggests that the main factors in ensuring successful change are giving ownership to people, providing and communicating a clear vision, empowering people, and leadership $[3,4,5,6]$.

Although there is wide agreement that empowering people, facilitating team work and (autonomous) team decisions are necessary in the decision-making process, many well-known pitfalls exist. These include self-censorship, higher risk-taking behavior, and stereotyping which can lead to defective decision-making and reduced performance.

However, communication, shared mental models and beliefs can help to avoid those problems and therefore are seen as crucial aspects in team decision-making [7]. As a consequence, suitable methods and tools must be provided to ensure such beneficial conditions when empowering teams to participate in process (re)engineering. One of the methods that may support team decision making in this way is LEGO® SERIOUS PLAY® (LSP).

\subsection{The LSP Method}

Lego Serious Play® (LSP) was originally developed to facilitate the strategy building process of the LEGO Company. LSP can best be described as a facilitated workshop where participants respond to tasks by building symbolic and metaphorical models with LEGO bricks and subsequently presenting them to the other participants. The LSP method is built on some basic values, like "The answer is in the system", "Everyone has to express his/her reflections" and "There is no ONE right answer". 
Participants are enabled to interact in a non-judgmental, free-thinking and playful way and can therefore work towards developing a common understanding, creative ideas etc. $[8,9]$. LSP is founded on four main constructs:

1. the importance of play as a way to learn through exploration and storytelling

2. constructionism

3. the hand-mind connection as a path for creative and expressive thinking

4. the role of the different kinds of imagination

In a typical LSP workshop the participants are first asked to build their perception of a particular problem. In the creative and spontaneous building process that follows, the participants give meaning to their models. Afterwards each participant explains the underlying story of his or her model to the others. Participants must respect the model and its meaning but they are allowed to ask questions to clarify details. In an LSP workshop the individual models can be used to build a shared model, to draw connections, and to create a landscape with so called 'external agents'. In a concluding reflection part the group creates insights $[8,9,10]$. The whole model can be the basis for playing, for analyzing particular scenarios, and finally extracting guiding principles [8].

The LSP method has already been applied to a multitude of problems $[9,10,11$, $12,13]$. Considering the mechanisms and theories inherent in the method it can be expected that it also lends itself to positive team decisions in the context of reengineering any kind of processes.

Table 1. Research design

\begin{tabular}{l|l}
\hline Component & Equivalents \\
\hline The study's questions & $\begin{array}{l}\text { Is LSP a suitable tool to support also the collective / parti- } \\
\text { cipative reengineering of a more or less creative process } \\
\text { like product development? }\end{array}$
\end{tabular}

The study's proposi- LSP supports collective decision making when reengineertions ing a design process - typical deficiencies are avoided. Participants are satisfied with the process.

Participants show a high identity with the result.

The study's units of The reengineering of a "product development lifecycle" analysis process with a certain number of participants from different departments.

The logic of linking the data to the propositions

Observed and self-reported qualitative variables lead to conclusions regarding the propositions.

The criteria for inter- Number of observed groupthink events during the reengipreting findings neering process, self-reported satisfaction, identification and acceptance from the participants, tangible outcome of the reengineering process. 


\subsection{Methodology and Propositions}

A case study approach was chosen as the research methodology. A case study can be described as the "detailed examination of a single example of a class of phenomena" $[14$, p. 34]. It is useful in providing hypotheses, which may then be tested systematically later on with a broader empirical basis [15].

A case study research design usually has the following components displayed in table $1[16,17,18]$ with its equivalents in our particular case.

\section{Case Study Analysis}

\subsection{Case Description}

This case study examines the impact of LSP as a tool in creating an effective Product Development Life Cycle (PDLC) process in which it is necessary to clearly define each functional role and respective responsibility. The company involved in the case study is a global medical device development and manufacturing business with headquarters in the USA and a number of operations worldwide including Ireland. The company had undergone a period of rapid growth and this resulted in functional areas roles and responsibilities both overlapping and separating from each other. The result of this rapid growth led to confusion around functional roles and responsibilities. However, development teams are required to work very closely together to support PDLC processes in order to reduce time to market. Of interest to the researchers was whether or not improvements to the PDLC process could be made using LSP tools and techniques. To this end, a one-day workshop was convened. The workshop was conducted off-site, over a seven-hour period and was facilitated by a certified LSP facilitator. Detailed observations were made throughout the workshop by another independent person. At the end of the day feedback was elicited from participants using group reflection exercises and an individual questionnaire survey. The workshop design followed the typical LSP setup as explained in chapter 2.2.

At the outset, the participants declared that they had an open mind and no particular expectations at the start of the workshop. They were aware that the workshop involved the use of Lego and that the theme was defining functional roles and responsibilities during New Product Development Life Cycle (NPDLC) processes. The purpose was to create collaborative clusters working together towards a common goal. The challenge included how best to provide an authentic collaborative environment through learning activities to achieve a set of objectives. The Groups involved in the workshop were from three functional areas in the company and involved eight senior management participants ( 2 female and 6 male). The groups comprised the following:

- Research \& Development (4 personnel)

- Regulatory Affairs (2 personnel)

- Design Assurance (2 personnel)

The workshop program involved (1) the introduction of participants and a brief introduction to LSP rules; (2) LSP skills building; (3) the building of individual and shared 
model(s) of the as-is- product development cycle; (4) the building of role models (group work); (5) the building of a shared model of a future product development lifecycle (aspiration) and the assignment of the different roles and their responsibility; (6) a final discussion with a conclusion and reflection and the agreement on further steps.

Each member was allocated an LSP kit and very quickly became familiar and comfortable with the workshop requirements. The 3D models built by each individual/group served as a communication tool and provided for a collaboration space to develop group responses and to trigger questions, see as an example fig. 1. From an observer's perspective this provided for peer-input and evaluation exercises and allowed knowledge sharing amongst the wider cohort. Obviously the 3D models acted as useful representations of proposed processes and allowed areas of overlap, redundancy, gaps and complications to be identified in a transparent way.

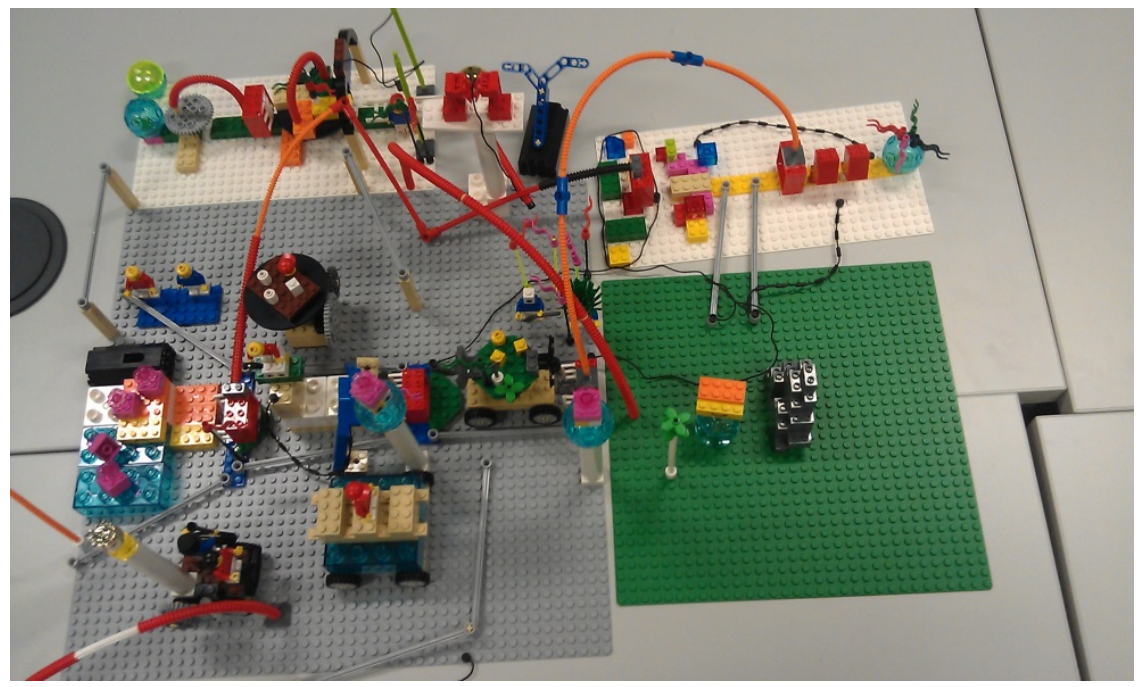

Fig. 1. Shared model of the future product development lifecycle

\subsection{Evaluation Results}

The feedback from the participants provided in the questionnaire centered around the following themes of collaboration challenges, resolution techniques and the resulting benefits. In answering the question "Is LSP a suitable tool to support the collective/participative reengineering of a more or less creative process like product development?" the following comments can support that this is the case.

- "Getting the group to engage openly and honestly with each other"

- "Ensuring everyone engaged openly and honestly in group discussions"

- "A lot of conflict within the group - was aware of this before the session and wasn't sure if it would work"

- "Pre-defined opinions strongly held" 
- "Integrating models developed individually with the group models"

- "Differing views on process descriptions"

- "Definition of roles and responsibilities. Understanding of the process steps and stages from different departmental prospective in the PDLC"

- "Understanding/not knowing other members needs and perspectives"

- "Lack of clarity of roles"

- "Not all aligned back at the day job"

The participants explained how they resolved the challenges of working in a group:

- "Using the Lego we built models current and future that facilitated very good discussion"

- "Open communication, respect the viewpoint of others, spoke about the model and addressed questions to the model and not to the person presenting"

- "Through sharing ideas through building and discussing ideas through the models"

- "Rotated the presentation role, ensured everyone spoke to the model so that it wasn't personal"

- "Everyone respected the others opinion within the context of the exercise"

- "Model was independent of personalities and functions/departments"

In answering the study's proposition that LSP supports collective decision making when reengineering a design process and hence typical deficiencies are avoided, the following comments were made with respect to group/team engagement.

- "Having the three groups working together without any disruption and focused on one objective"

- "Developed closer ties between individuals and teams".

- "Building on the existing relationship between all members of the team"

- "Establishing group views for later discussion"

Those comments are supported by the independent observer who didn't identify any deficiencies in the group decision making process.

With respect to understanding roles and responsibilities, the participants rated understanding of each other's roles and responsibilities as a benefit and also highlighted the positive aspects of the experience. In terms of shared understanding for future growth, the participants recognized the need for growth and progress and felt this could be achieved through LSP. Benefits gleaned from the LSP experience included: "Listening to current state of affairs and preferred future state"; "Hearing other ideas and perspectives"; "Individuals take visual ideas from one another"; "Discussing ideas and challenges"; "Agreeing that future/continued actions are necessary to create an agreed strategy"; "More focus on the bigger picture"; "Bonding and alignment of views"; "Shared understanding was developed".

\subsection{Advantages and Disadvantages}

Whilst the participants appreciated working with visual tools and clearly identified the 'real-world' relevance of replicating industry scenarios and problem-solving activities 
through 3D models they were aware of the time required by this process. They also stressed the need for follow-up to implement the new model in the form of a written plan of action. It was also suggested that non-attendees may not take the process seriously so translating the output to the organization in a suitable manner would be important.

All the participants were satisfied with the workshop experience and agreed that working with LSP provided them with a deep learning experience and engagement with the group. The positive dynamic and confidence of all grew and they came to a shared understanding on the team goals as a result. The reasons for the positive outcomes fit with former research results proofing that the LSP methodology gives ownership to people, provides the possibility to express clear visions and leads to a shared understanding by an easy modelling technique.

\section{Conclusion and Future Research}

The responses from the participants indicate that incorporating LSP as a support tool for NPDLC resulted in extremely engaged and creative managers who became absorbed in a process of improvement. The responses also highlight that the objectives set at the start of the workshop were achieved. The results suggest a deeper understanding of NPDLC roles and responsibilities than previously. Also engagement with the process was enhanced as participants were required to use higher level cognition. The groups also rotated the leadership role and this facilitated group problem solving, communication and improved leadership skills. Perceived disadvantages of LSP were minimal.

The company intends to address and resolve gaps and misconceptions in the current PDLC process with respect to roles and responsibilities. It was agreed that an action plan would be developed and that a follow-up LSP workshop and review would take place in 12 months' time to determine what process improvement if any was achieved.

Further research will focus on evaluations on whether or not teams can function more effectively under different conditions. Variables to be considered may be problem's complexity and tangibility, group's heterogeneity, individuals' background, experiences and attitudes, situational parameters etc.

\section{References}

1. Lee, R.G., Dale, B.G.: Business process management: a review and evaluation. Business Process Management Journal 4(3), 214-225 (1998)

2. Grover, V., Jeong, S.R., Kettinger, W.J., Teng, J.T.C.: The implementation of business process reengineering. Journal of Management Information Systems 12(1), 109-144 (1995)

3. Paton, R.A., McCalman, J.: Change Management. Sage, London (2008)

4. Fritzenschaft, T.: Critical Success Factors of Change Management. Springer Gabler, Wiesbaden (2014) 
5. Cameron, E., Green, M.: Making Sense of Change Management. Kogan Page Ldt. (2012)

6. Trkman, P.: The critical success factors of business process management. International Journal of Information Management 30, 125-134 (2010)

7. Neck, C.P., Manz, C.C.: From Groupthink to Teamthink: Toward the Creation of Constructive Thought Patterns in Self-Managing Work Teams. Human Relations 47(8), 929952 (1994)

8. Kristiansen, P., Hansen, P.K., Møller Nielsen, L.: Articulation of tacit and complex knowledge. In: Schönsleben, P., Vodicka, M., Smeds, R., Riis, J.O. (eds.) 13th International Workshop of the IFIP WG 5.7 SIG, pp. 77-86. Eidgenössische Technische Hochschule Zürich (2009)

9. Hansen, P.K., Mabogunje, A., Haase, L.M.: Get a Grip on Sense - Making and Exploration Dealing with Complexity through Serious Play. In: Sun, H., Jiao, R., Xie, M. (eds.) IEEE International Conference on Industrial Engineering and Engineering Management, pp. 1593-1597. IEEE Press (2009)

10. Frick, E., Tardini, S., Cantoni, L.: LEGO®SERIOUS PLAY® - A state of the art of its applications in Europe. White Paper, Università della Svizzera italiana, Lugano, Switzerland (2013)

11. Hadida, A.: Let your hand do the thinking! Lego bricks, strategic thinking and ideas generation within organizations. Strategic Direction 29(2), 3-5 (2013)

12. Jentsch, D., Riedel, R., Müller, E.: Strategy and Innovation for the Production Systems of SME. In: Doolen, T., Van Aken, E. (eds.) Proceedings of the 2011 Industrial Engineering Research Conference (IERC), Reno (2011)

13. Jentsch, D., Riedel, R., Mueller, E.: Flow and Physical Objects in Experiential Learning for Industrial Engineering Education. In: Emmanouilidis, C., Taisch, M., Kiritsis, D. (eds.) APMS 2012. IFIP AICT, vol. 397, pp. 566-573. Springer, Heidelberg (2013)

14. Abercrombie, N., Hill, S., Turner, B.S.: Dictionary of sociology. Penguin, Harmondsworth (1984)

15. Flyvbjerg, B.: Five Misunderstandings About Case-Study Research. Qualitative Inquiry 12 (2), 219-245 (2006)

16. Darke, P., Shanks, G., Broadbent, M.: Successfully completing case study research: combining rigour, relevance and pragmatism. Info. Systems J. 8, 273-289 (1998)

17. Rowley, J.: Using Case Studies in Research. Management Research News 25(1), 16-27 (2002)

18. Yin, R.K.: Case study research; design and methods. Sage, Thousand Oaks (2003) 